\title{
Improving Innovation Education for Vocational College Students by the OBE Concept
}

\author{
Guangmei Lin ${ }^{1, ~ a}$, Kun Bai ${ }^{2, ~ b, ~ *}$, Zhen Kong ${ }^{1, ~ c}$, Linghan Kong ${ }^{3}$ \\ ${ }^{1}$ Beijing Information Technology College, No. 5, Fangyuanxilu, Chaoyang District, \\ Beijing, China \\ ${ }^{2}$ University of International Relations, No. 12, Poshangcun, Haidian District, \\ Beijing, China \\ ${ }^{3}$ Beijing Bayi School, No. 29, Suzhoujie, Haidian District, Beijing, China \\ ${ }^{a}$ Lingm@bitc.edu.cn, ${ }^{b}$ Baikun@uir.edu.cn, ${ }^{c}$ Kongz@bitc.edu.cn \\ *Corresponding author
}

\begin{abstract}
The objective of the vocational education system is to produce professionals as demanded by the nation for human resources. One purpose is to produce graduate students who will become productive and creative citizens. Entrepreneurship has emerged over the last two decades as arguably the most potent economic force the world has ever experienced. With that expansion comes a similar increase in the field of innovation education. Introducing the OBE concept into the innovation education will lead to a series of achievements in vocational colleges. While it can be argued that some legitimacy has been attained in the current state of this education, there are critical challenges that lie ahead. This article focuses on the trends and challenges in innovation education for the 21st century. An innovator is a person who does or undertakes something. Policy makers also believe that increased levels of innovation can be reached through OBE education.
\end{abstract}

KEYWORDS: Vocational college; Innovation; OBE; Entrepreneurial Thinking

\section{Introduction}

Since the first innovation class-held in 1947-the academic discipline of innovation education's growth is described using a chronology of three domains - courses, supplemental infrastructures and publications. Outcome-based education (OBE) is an educational theory that bases each part of an educational system around goals (outcomes). By the end of the educational experience, each student should have achieved the goal. There is no single specified style of teaching or assessment in OBE; instead, classes, opportunities, and assessments should all help students achieve the specified outcomes. The role of the faculty adapts into instructor, trainer, facilitator, and/or mentor based on the outcomes targeted. 
Outcome-based methods have been adopted in education systems around the world, at multiple levels. The OBE model comes from abroad and is widely used. The OBE concept runs through China's innovation education certification standards. Therefore, such education is promoted and implemented into school curricula in many colleges in China. Rethinking Education calls for a fundamental shift in education, with more focus on 'learning outcomes' - the knowledge, skills and competences that students acquire. Merely having spent time in education is no longer sufficient. In addition, basic literacy and numeracy still needs to be significantly improved, and entrepreneurial skills and a sense of initiative need to be developed or strengthened. To ensure that education is more relevant to the needs of students and the labor market, assessment methods need to be adapted and modernized. The use of open educational resources should be scaled-up in all learning contexts. Teachers need to update their own skills through regular training.

\section{Innovation Education in 21st Century}

China is giving a significant emphasis to the innovation education as it needs graduates who are creative, innovative and knowledgeable. These are the ingredients required to make the economy and the country into a high income and developed nation. Chinese distinctive approach to innovation education has enjoyed more than 10 years of growth, with accelerated growth in the 2010s when courses, endowed positions, centers and publications began doubling every year. In China, since 2014, "public entrepreneurship and mass innovation" has been a national strategy and the government had made great efforts to promote entrepreneurial activities. The Guidelines of the State Council on Promoting Public Entrepreneurship and Mass Innovation issued by the State Council in 2015 emphasized improving the system of mentoring, including the establishment of mentoring teams and the development of long-term effective mentoring mechanism to provide innovation mentoring services for young entrepreneurs. This policy initiative was driven by the finding that entrepreneurial successes are largely influenced by innovation mentoring, which has been adopted by many countries, such as the Business Link-PBA (Professional Business Advisor) in UK. The OBE innovation education system in the Chinese environment has its distinctive features and faces many problems. The main challenges of this system also include the issues of poor quality of mentors, arbitrary supervision, and unavailability of incentive mechanism and so on. What are the implications of these trajectories of growth for this field in vocational colleges? It is safe to say that the life cycle of innovation education is at the threshold of the maturity stage. The orthodoxy and mainstream opportunities that have come as innovation education's payoff for success also pose the very real threat of less variance in thinking, in depth or quality of relation to the entrepreneurial community, and in the distinctiveness of the domain of entrepreneurship research. The big problem is avoiding stagnation. Entrepreneurs are warned about the danger success brings-getting complacent with success and forgetting about the energy, innovation and market orientation that originally made them successful. Today, lack of faculty at every rank is the number one limiting factor of the growth of the field because demand has outstripped the supply of courses and faculty, imbued with the challenge 
to look at the broader societal context in which innovation education is enmeshed, would do much to strengthen and adapt this field. Innovation education is succeeding beyond anyone's past predictions. One future uncertainty is the form or forms of innovation education that dominate in the new century. The next new paradigm could come from anywhere on the globe, emerging from the new infusions of culture, business settings and institutional influences. For the 21st century version, the world could turn anywhere.

\section{Empowering Students through OBE}

Traditional instruction, such as the typical lecture-based session, often involves delivering as much information as quickly as possible. The lecture method was one of the most effective and efficient ways to disseminate information and has often been used for this end. Students, not knowing how to be active participants in the lecture, have relied on transcription, memorizing and repetition for learning. In recent decades, however, we have learned a great deal from cognitive science research about the nature of learning. Students construct knowledge; they do not take it in as it is disseminated, but rather they build on knowledge they have gained previously. They benefit from working together and they may learn best from teaching each other. Research also suggests that students learn best in the context of a compelling problem; they learn through experience. This relatively new information suggests that teaching is a complex activity and it necessitates the emergence and development of approaches to instruction that are consistent with what we know about the way learning happens. This new understanding has given rise to the notion of a paradigm shift in higher education, one from a focus on teaching to a focus on learning. In China, Beijing Information Technology College has realized the need for an outcome-based approach for continual improvement in innovation education. The results have led to some introspection. The higher education institutions started to respond to a growing concern for the adequacy of students' professional and career preparation by specifying the outcomes or abilities that were demanded in the market. Such outcomes are programmed to focus on assessing performance as well as knowledge, bridging the gap between college and career world. This approach is important and corresponds with the global education concept of outcome-based education (OBE) rather than the traditional pedagogical teaching. This is to ensure each of the programs is able to generate a holistic, successful student in the academic field and magnificent human capital. OBE emphasizes the necessity of a structured curriculum that is organized and practical, with the purpose of generating a versatile graduate who can understand and master the said curriculum. In line with this, various steps, processes and systems have been developed to document the implementation of OBE. Technology, in particular the internet, must be fully exploited. Colleges must increase access to education via open educational resources. These reforms must be supported by well-trained, motivated and entrepreneurial teachers. 


\section{Future Challenges}

Innovation educators must be more than cheerleaders. We can no longer simply say 'innovation is different.' Innovation is now a part of the mainstream. Guarding the past, espousing orthodoxy, and refusing to see the wisdom inherent in the challenges of the young and inexperienced will lead to the same problems in education as in business. Some educators have a "pioneering passion" and others have "survival" mentality. It is an age of fighting for a cause. Some colleges in Beijing have developed and promoted an "experiential classroom” for innovation education. These programs must be continued, supported, and enhanced. Organizations need to support this effort as part of their mission. Our classrooms became infatuated with the drive for investment and liquidity, fast cash, quick exits, and no real commitment. We pursued an "investment mentality" rather than facilitating the search for an "enduring enterprise." We must again focus on the real goals of innovators and the motivation that permeates from them. We must educate our next generation of innovators to learn from the dot-com evaporation and return to the roots of business formation. After reviewing the major challenges that are confronting all of us as innovation educators, the question remains, "So what can I do?" The answer is neither complex nor profound. The answer is really an aggregation of numerous small but needed actions. Remember, the journey of 10,000 miles always starts with the first step! It has been said that one definition of insanity is "doing the same thing and expecting different results." Therefore, the emerging generation of educators faces the difficulty of forgetting old idea and taking actions. An innovation teacher is a person who does or undertakes something. In a review of the terminological history of the word, Robert Hébert and Albert Link came up with a list of 12 overlapping definitions, whose commonality is that they all speak of an action to be undertaken. Action orientation, a determination to have agency in this world, is of course a property characteristic of innovation. This is a much larger topic still, but my own utopian hope is this: innovation teaching may yet be a place where some of the academic renewal takes place that we all want and need.

\section{Innovative Thinking}

Innovative thinking wants to make things happen. This thinking is also willing to take action where the outcome is less than certain, to venture where others hesitate, to see possibilities where others only see problems. Hence, innovative thinking embraces possibility and enables leadership. The thinking is action-oriented and team-oriented; it has a multiplier effect. It starts from a need to act on something - a problem, an idea, an opportunity. And it brings people together around a project. The Art of Possibility is the title of a book by Rosamund Stone Zander and Benjamin Zander - a psychotherapist and an internationally known conductor, respectively. They point out the obvious: that many of our frameworks for action are really inventions. On the one hand, this is a commonplace notion, since entrepreneurs of any sort would not start their projects if they did not hope for success. On the other hand, if we extend the concept of hopefulness beyond the 
venture itself to the people involved in it, it acquires new significance. Innovation involves an act of self-creation and self-expression, self-invention or re-invention, a stepping out beyond the known boundaries of the self. Innovative thinking is different from management thinking and from the thinking that has pervaded traditional management education, in which an undercurrent of cynicism co-exists uneasily with faith in human nature. In innovative thinking, faith in human potential to behave rationally and decently tends to have the upper hand. The thinking always aims at improving something would also appear to be a self-evident characteristic, except when we begin to define "innovation" in very broad terms, far beyond business applications. I believe that this is exactly what needs to be done.

\section{Summary}

Education plays a vital role in the quest of developing human capital and knowledge workers. OBE has compelled many faculties to re-examine the programs as well as the courses offered, to consider if they are aligned with the requirements of the human resource managers. However, the increase is marginal and therefore can be further improved in the forthcoming semesters. In addition, lecturers are able to assess their performance and take corrective actions to further improve their teaching and learning methods and styles. The OBE implementation can be further improved and enhanced. It is an on-going and evolving process. In short, the introduction and implementation of OBE at the faculty and college is timely in accordance with the employers' demand of the graduates. The college management needs to motivate and promote OBE implementation at all times so that the momentum can be sustained and therefore can achieve the stated objectives. All parties concerned, i.e. students, lecturers, administrators and the college decision-makers should co-operate and work as a team in realizing the OBE objectives. This could be the new way to fulfill the mission of education.

\section{Acknowledgements}

This research was financially supported by Beijing Information Technology College Research Subject.

\section{References}

[1] Spady William, Outcome-Based Education: Critical Issues and Answers[M]. Arlington Virginia, 1994.

[2] Jerome A. Katz, The chronology and intellectual trajectory of American entrepreneurship education[J]. Journal of Business Venturing 2003 (18) 283300.

[3] Ting, S. X., Feng, L., \& Qin, W., The Effect of Entrepreneur Mentoring and its Determinants in the Chinese Context[J]. Management Decision, 2017(8) 1410-1425.

[4] Kaliannan, Empowering Students through Outcome-Based Education (OBE) [J].Research in Education, 2012(87)50-63. 